\title{
Objetualidades vulnerables: una mirada desde los Estudios Visuales
}

\author{
María Elena Lucero ${ }^{\bullet}$ \\ Universidad Nacional de Rosario
}

\begin{abstract}
Resumen
Dentro de un contexto internacional que impulsó la abstracción, el informalismo y la experimentación matérica, y tras la presentación de Arte Destructivo en la Galería Lirolay de Buenos Aires en 1961, algunos artistas argentinos ensayaron la utilización de elementos precarios ensamblados, con grosores y texturas pictóricas. Durante los sesenta Rubén Santantonín construyó un conjunto de obras denominadas por él mismo «cosas», y a comienzos de la década siguiente Víctor Grippo comenzó a trabajar con papas, cables y metales. En este artículo consideraremos los trabajos de Santantonín y de Grippo en el marco de los aportes teóricos de los Estudios Visuales, destacando aquellas bases materiales que convierten sus producciones en objetualidades vulnerables, inmersas en una estética vigorosa y sensible.
\end{abstract}

\section{Palabras clave:}

Rubén Santantonín · Víctor Grippo · Estudios Visuales objetualidades · vulnerabilidad 


\begin{abstract}
Within an international context that promoted abstraction, informalism, and material experimentation, and after the presentation of Arte Destructivo at Lirolay Gallery in Buenos Aires in 1961, some Argentine artists experimented with the use of assembled impermanent elements, featuring pictorial textures and thicknesses. In the sixties, Rubén Santantonín created a set of works that he himself called "cosas» («things»), and in the beginning of the following decade, Víctor Grippo started working with potatoes, wires, and metals. This article examines the works of Santantonín and Grippo in the context of the theoretical contributions of Visual Studies, focusing on the material bases that turn their productions into vulnerable objectualities, immersed in a vigorous, sensitive aesthetic.
\end{abstract}

\title{
Key words:
}

· Rubén Santantonín · Víctor Grippo · Visual Studies · objectualities vulnerability

\section{I}

Durante los años ' 50 las corrientes vinculadas al informalismo tuvieron una fuerte presencia en la esfera artística internacional, instaurando modos de producción en los cuales el artista acudía a determinadas técnicas específicas caracterizadas por la aplicación de texturas, las mezclas de pigmentos con sustancias engrosantes, los volúmenes incorporados a las telas, la aplicación de objetos, grosores heterogéneos, etc. La expansión de la denominada pintura matérica abrió paso a numerosas experiencias que, a la par del triunfo geométrico que marcó a gran parte del arte moderno, ampliaron el arsenal de herramientas expresivas en pos de una mayor gestualidad. Dicha condición concordaba con episodios sociales conflictivos y estertores mundiales tales como el fin de la Segunda Guerra mundial y el surgimiento de un clima de enorme tensión política de la mano de la Guerra fría.

En el campo local, en 1961 se inauguró la muestra Arte Destructivo en la Galería Lirolay de Buenos Aires, integrada por Kenneth Kemble, Antonio Seguí, Jorge López Anaya, Enrique Barilari, Olga López, Jorge Roiger, Silvia Torras y Luis Wells. En el manifiesto redactado en el mismo año, Kemble hacía referencia al carácter experimental de la exhibición, invitando al espectador a desplazarse hacia el terreno de la aventura y lo desconocido, donde la existencia del arte se conectaba con necesidades humanas vitales. Dentro de ese conjunto de emociones también afloraba la destrucción como un instinto, como una reacción o un sentimiento lícito: «La destrucción directa, física, activa o de hecho por medio del hacha, el martillo, el cuchillo, el fuego, los ácidos, la pólvora, las balas, etc.; la destrucción en 
cuanto es intención o sugerencia», así como «la destrucción de la lógica de un texto previamente existente por medio de la descomposición casuística y verbal realizable con métodos varios» (Kemble, 1961 en Cippolini, 2003: 294). El tono rupturista y por momentos turbador, tanto de las palabras como de las obras mismas, hicieron de Arte Destructivo una propuesta que aglutinaría el desgarro, la convulsión o las heridas, afectividades coexistentes en el panorama mundial. Dicho momento fue identificado por Andrea Giunta como un trecho donde no solo las vanguardias se convierten en el mismo repertorio de los movimientos emergentes por lo cual se «las revisitaba para activarlas desde las preguntas del presente» (Giunta, 2014: 24), sino que se plantea una sincronización de problemáticas comunes en el ámbito estético global, tanto en países latinoamericanos como en Nueva York o Japón.

Por entonces Rubén Santantonín (1919-1969) incorporó en su quehacer artístico materiales como yeso, alambre, papel, cartón o telas gruesas, configurando un conjunto de objetos que eran instalados y suspendidos del techo. Sus obras, nombradas por el artista como "cosas», fueron expuestas en Lirolay junto al trabajo de Luis Wells, en el mismo año en que se desarrolló Arte Destructivo. En el texto del catálogo, Santantonín utilizó expresiones como «encrucijada existencial»o «devoción existencial», las cuales dejaban en claro «la dirección del programa santantoniano y su divergencia con el pop-art. El existencialismo es una de las corrientes filosóficas más influyentes de la posguerra», y proponía la confluencia de la actividad artística con la responsabilidad social de fomentar "la conformación de un nuevo humanismo" (Alonso, 2013: 37). En esos términos se fue definiendo la trayectoria de un artista vinculado a las actividades del Di Tella y a sus protagonistas pero con un impulso filosófico y creativo peculiar. Más tarde, del 19 al 31 de marzo de 1962 y también en Lirolay, Santantonín participó de "Collage (13 pintores)». Las superficies de los trabajos eran voluminosas y prominentes, recubiertas de papel pintado en general con tonalidades monocromas y opacas. Estas protuberancias cuyos volúmenes parecían hincharse como bultos o aglomeraciones, tornaban a las obras cuerpos extraños, invasivos. En 1962 y 1963 el artista integró los Premios Ver y Estimar, ambas ediciones desarrolladas en el Museo Nacional de Bellas Artes de Buenos Aires, obteniendo el Premio de Honor en el 62 con «S/T», una obra de cartón recubierta con papel gris oscuro de 1961 una serie de montículos que simulaban redondeces, corpúsculos u organismos petrificados (Figura 1). Al año siguiente Santantonín presentó un armazón de contorno irregular casi como una enorme cuña, recubierto con telas oscuras y con volúmenes incrustados en un interior. La presencia de hoyuelos le otorga un aspecto de cráter o superficie lunar, a la vez que genera un sentimiento de misterio del relleno/contenido oculto. Sustancias inquietantes y construcciones perturbadoras que remiten a un sentido subrepticio, endurecido por la fuerza manual ejercida sobre las telas al agujerear, cortar, comprimir, rasgar. 


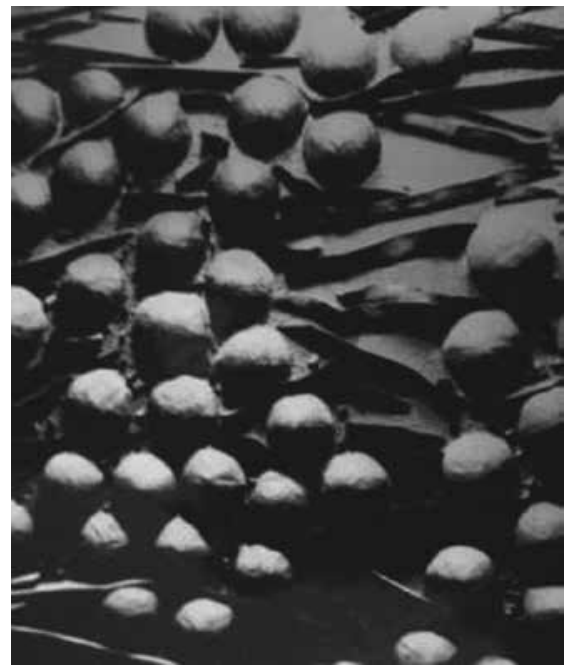

Figura 1. Rubén Santantonín «S/T», 1961 (detalle)

Relieve, técnica mixta, materiales diversos Crédito: Archivo de la Biblioteca del Museo de Arte Moderno de Buenos Aires

Es necesario considerar el papel que Santantonín desempeñó en las actividades del CAV (Centro de Artes Visuales) del Instituto Di Tella. En 1963 el CAV tenía su local en la calle Florida, y fue la sede de una actividad frenética, dinámica y arrolladora, liderada por el crítico de arte Jorge Romero Brest. En ese año el artista formó parte del Premio Nacional Di Tella, efectuado en el mismo Instituto, y fue invitado a participar de la VII Bienal de Arte de São Paulo. En el catálogo de Premio Di Tella, escribió:

(...) la imaginación no partía de mí hacia afuera, sino que se gestaba en mí llegándome del mundo exterior, hería mi fuero humano y así imaginaba, imagino, es decir hago imagen del mundo fuera de mí, contaminando mi ego.

Y del mundo exterior quiero imaginar a mi tiempo, el tiempo de nuestra circunstancia, en su potente interioridad, que está a la vista invisiblemente (...)

Porque amo a mi tiempo así como es, cruel, descarnado, frenético, precario pero verídico. Lo amo porque está probando que puede existir con el no-juicio, en el desvalor, ardientemente, aceptando su realidad, la realidad de su dolor joven, la realidad del dolor nuevo de mi tiempo (...)

Santantonín, Mayo 1963 (en Kemble y Santantonín, 1963: 58-59)

Las obras de Santantonín transmiten significados ligados a la inquietud, a la extrañeza y hasta a la violencia, aunque en sus escritos ha colocado el acento en el aspecto ontológico de estas materialidades. En «Por qué nombro "cosas" a estos objetos» de 1964 proponía específicamente una distancia entre el «objeto» $\mathrm{y}$ «cosa»:

Hay algo en el objeto que hace que el hombre se sienta enfrentado por él. Como si lo La COSA como preocupación artística del problema, es el acontecer del objeto. ACONTECE gracias a esa vida que le prestamos al concebirlo como COSA. Pues en tanto le quitemos la adhesión que ese préstamo implica, volverá a ser objeto irremediablemente. Entiendo a la COSA como la prevalencia de lo humano sobre los objetos, la poesía vital del objeto.

Esta nueva plasmación debe ser concebida como COSA, en singular, pues así alcanza la significa- 
ción buscada: la COSA entendida como expresión. No debe ser interpretada como «un arte de las cosas», lo que haría suponer en cierto modo un arte-reflejo. Ni ser tomada como la mera colocación de objetos en el mundo, pues aspira a lograr el desdoblamiento del hombre en las cosas (...)

Santantonín (en Santantonín, 1964)

Estas definiciones no siempre fueron traducidas en términos deseables. De hecho para Jorge Romero Brest los planteos de Santantonín mantenían una posición idealista y romántica: «Lenguaje todavía romántico de quien no pudo superar las pasiones y finalmente quedó encerrado en la COSA (...)» (Romero Brest, 1969: 71). Más que romántica, la perspectiva teórica del artista demarcó una posición filosófica que abordaba la cosa misma como una superación del concepto de objeto donde «la cosidad que describe en relación al constructo plástico remitía no solo a la intervención humana sino a un exceso matérico (captado en los cúmulos de texturas y superficies rematadas) que anulaba la figuratividad o la representación mimética» (Lucero, 2017). Desde esa mirada podríamos leer un pasaje a cierto de estado de lo vulnerable debido a la transitoriedad y al desgaste o erosión de los componentes que integraban las "cosas». Frente al uso de ingredientes duraderos, Santantonín acudió a elementos de improbable estabilidad. Nos referimos a un abordaje de la vulnerabilidad en tensión con el tiempo que transcurre y con un proceso inevitable de deterioro físico. Otro tanto ocurre en «Aéreo» de 1964 (Figura 2), una construcción hecha de alambres, gasas blancas, papeles opacos y plateados, todos ellos pegados y superpuestos rudimentariamente y de modo efectivo. Colgando del techo, esta "cosa» mediaría entre un aerostático, una formación planetaria, una cápsula, una estructura cavernosa, una magnífica medusa primitiva. De funcionalidad ambigua, la obra proporciona incertidumbre en relación a su significado y por su posición en el espacio, pero a la vez seduce, hechiza y atrae, nos interpela por su volumen generoso como una aparición infrecuente, casi fantasmática.

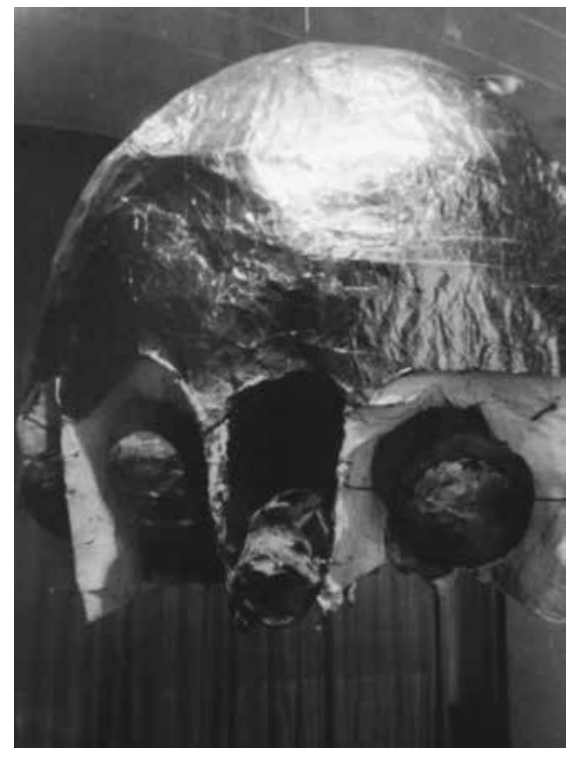

Figura 2. Rubén Santantonín «Aéreo», 1964

Técnica mixta, materiales diversos

Crédito: Archivo de la Biblioteca del Museo de Arte Moderno de Buenos Aires 


\section{II}

Durante $1966^{1}$, los artistas Kenneth Kemble, Enrique Barilari junto a Emilio Renart y Víctor Grippo firmaron un texto colectivo llamado «Proceso de creación», donde plantearon la conjunción de cálculo y riesgo, orden y aventura, creación y destrucción como coordenadas que palpitan en la existencia humana y en los procesos de la práctica artística. Tanto Kemble como Barilari habían sido protagonistas de Arte Destructivo, y sostenían un ejercicio crítico en relación a los pronunciamientos conceptuales que surgieron a inicios de los años ' 60 respecto a una situación de caos, de conflictos y tensiones irresueltas en el ámbito nacional e internacional. Los cuatro artistas formaron un grupo de estudio que postulaba al acto creativo como una dinámica en permanente desarrollo e incorporación al campo social. En ese itinerario, desestimaron la inspiración o los «raptos emotivos» que identificaron la labor plástica durante largo tiempo, aspirando a "ser artistas o creadores integrando las frases del mismo modo con que pretendemos integrar la sociedad: como sujetos determinados por un quehacer específico al que es posible acceder con intención y libertad». Uno de los puntos más destacados del texto se apoyaba en la aceptación de las «diferencias expresivas» por la falta de desarrollo de medios como un aspecto productivo que conducía al progreso humano individual, y no como falencia o «lacra» que debería esconderse, señalando una «canalización positiva de la creación" (Renart et al. en Amigo et al., 2010: 56-57). La capitalización de estos condicionamientos abría nuevos sentidos para los procesos artísticos.

Estas afirmaciones instituyen la antesala de la obra de Víctor Grippo, autor de una propuesta visual penetrante, de gran densidad semántica que lo llevaría a articular lo que se planteaba a nivel grupal: la conexión entre orden (estructura, diagramación) y aventura (desbordamiento, crecimiento). Con formación en el área de la química, Grippo recurrió a una figura emblemática de la cultura culinaria latinoamericana, la papa, cuya función básica es la alimentación. Mediante la interlocución entre dos polaridades, naturaleza/cultura, la papa se relaciona con la conciencia crítica de la energía al ampliarse su función cotidiana, produciéndose una suerte de analogía literal entre el tubérculo (que contiene de manera latente la fuerza para la subsistencia), la energía y la conciencia de la misma. Estas reflexiones tomaron cuerpo en «Analogía I» de 1970-1971 (Figura 3), una repisa doble de madera blanca con compartimentos en los cuales colocaba papas con cables, electrodos (uno de cobre y otro de zinc a cada una de las papas) y voltímetro, aparato para la medición de la energía. 


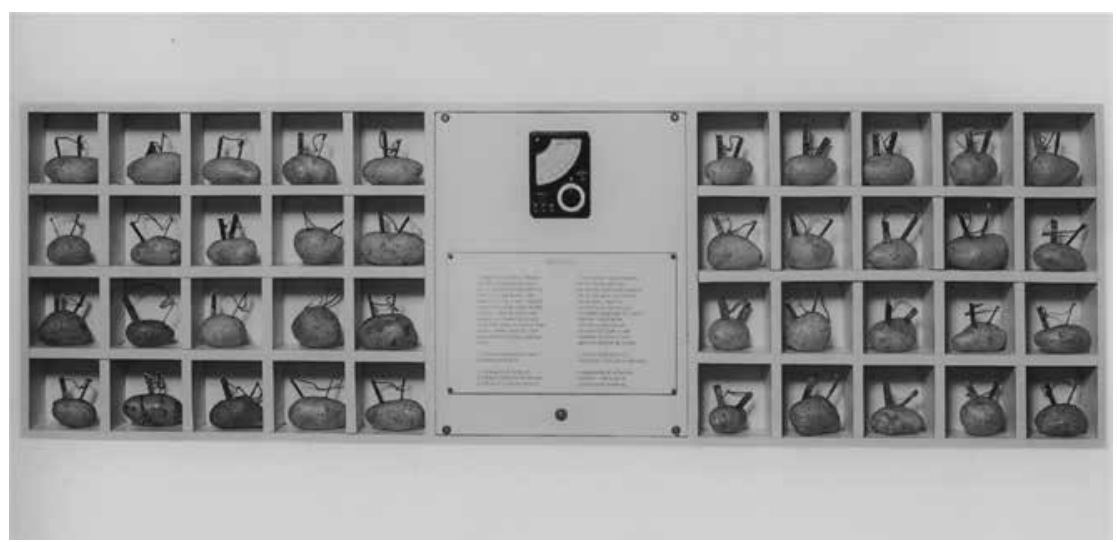

Figura 3. Víctor Grippo

«Analogía l», 1970-1971

Técnica mixta, papas, cables, madera

Crédito: Cortesía de Nilda Olmos de Grippo

La convivencia real de un producto de la tierra (vinculado además a la nutrición de los pueblos andinos) y los fragmentos de cables y trozos de metal incrustados en las papas, alcanza una dualidad singular y dialógica. Por la técnica podemos calcular la energía del alimento, el cual conlleva en sí mismo las propiedades básicas para generar salud y conciencia. Una conciencia que es crítica, reflexiva y libertaria. Con el avance del tiempo la papa evidenciaría cualidades naturales que cambiarán su aspecto externo, cada vez más rugoso, amarronado, ceñido, hasta perder su humedad y descomponerse. La inevitable putrefacción del vegetal por la intromisión de bacterias, hongos o elementos contaminantes, cambiarán el sentido del experimento que propone su autor, advirtiendo la condición vulnerable y/o perecedera del alimento en la generación de ciertas sustancias de carácter gaseoso. En el texto escrito de 1971 que compartió junto a Alberto Pellegrino y Alfredo Portillos (publicado con motivo de la exhibición "Arte de sistemas» en el CAYC), Grippo especificó la analogía a partir de las relaciones entre la papa y la conciencia:

1. Papa: (voz quichua) Nombre primitivo de la papa que aún se usa en España y en toda América. Tubérculo: papa de apio, fam. Paparrucha. Fig. y fam. Cualquier especie de comida. Sopas blandas y puches. Papa de cańa o real; aguaturma: Planta compuesta comestible. América central: Papa del aire. Name cimarrón. Chile, papa espinosa. Bolivia, papa lisa, ulluco.

2. Función cotidiana de la papa: Alimentación Básica.

3. Ampliación de la función cotidiana: Obtención de energía eléctrica ( 0,7 volt. Por unidad)
1. Conciencia: Conocimiento, noción. Deriva del latín conciencia. Sentimiento interior por el cual aprecia el hombre sus acciones. Nuestra conciencia es nuestra jura. Moralidadintegridad. En sentido figurado: libertad de conciencia, derecho que reconoce el Estado a cada ciudadano de pensar como quiera en materia de religión.

2. Función cotidiana de la conciencia: conciencia individual.

3. Ampliación de la función cotidiana: obtención de conciencia de la energía. 
Posteriormente, retomaría esta iniciativa complejizando la operación y elaborando una instalación de mayor envergadura. En 1977 efectúa una versión de «Analogía I» en la sede del CAYC (Centro de Arte y Comunicación) y una segunda en la XIV Bienal de São Paulo en Brasil. La cantidad de papas aumentó y también el sistema de cableado, el cual estaba conectado a un mecanismo que monitoreaba el cálculo de la energía. En este caso, a mayor interacción, mayor medición y generación de conciencia, la mutación del alimento en energía adoptaba una definición doble: la alquímica (papa en fuerza) y la especulativa y/o filosófica (energía que redunda en un crecimiento de la conciencia crítica). Por otro lado, aparece en juego el rol del artista-técnico que tantea, ensaya y sondea en los mecanismos que empalman arte y ciencia, apuntalando al logro de objetivos comprobables: la transformación de un elemento tangible en otro menos aprehensible, y que en definitiva, deriva en el terreno del pensamiento, lo que denominó "conciencia crítica». A grandes rasgos, la fusión de dimensiones naturales y artificiales dan como resultado un entramado matemático (papa + energía: conciencia crítica) que desemboca en una gran metamorfosis orgánica, corpórea y a la su vez inasible a simple vista, estimulando procedimientos ceñidos a la incorporación, canalización, conversión y liberación de sustancias vivas.

En 1980 Grippo presentó «Vida, muerte y resurrección» (Figura 4), una vitrina en cuyo interior había figuras geométricas hechas de láminas de plomo rellenas de porotos, a los cuales se les agregaba agua para que inicien el proceso de germinación. Con el correr de los días las semillas comenzarían a hincharse, abriéndose paso por entre las hendijas de los cinco pares de cuerpos volumétricos y derrapando por los costados. Mercedes Casanegra ha definido como "estética activa» a un sector de obras de Grippo en las cuales «existe un factor activo que desde un determinado momento se pone en movimiento, en marcha, y comienza a producirse una transformación. Se desencadena un proceso que, a menos que un accidente se interponga, no se detiene: está realmente vivo» (Casanegra, 1993: 14).

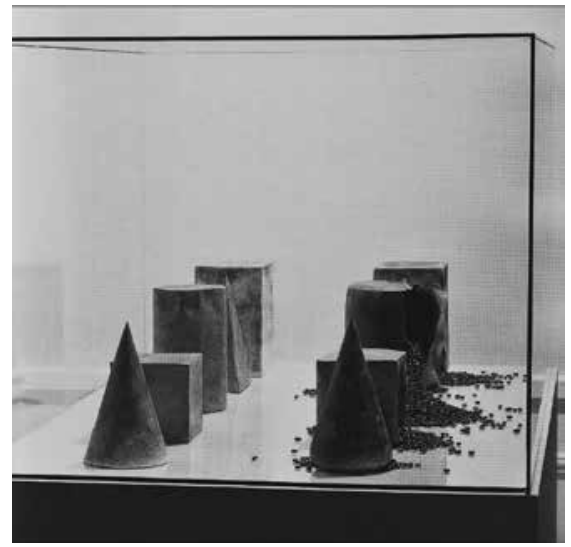

Figura 4. Víctor Grippo

«Vida, Muerte, Resurrección», 1980

Técnica mixta, plomo, semillas, vidrio

Crédito: Cortesía de Nilda Olmos de Grippo 


\section{III}

Tanto las producciones de Rubén Santantonín como de Víctor Grippo se han identificado con una etapa del arte argentino cruzada por el informalismo pictórico, los crecientes dinámicas de desmaterialización del objeto, los accionismos, la injerencia de los medios masivos de comunicación o por los procesos conceptuales direccionados hacia el llamado «arte de sistemas». Intentaremos establecer una lectura de los itinerarios visuales de ambos artistas considerando algunas nociones de los Estudios Visuales y teniendo como epicentro la materialidad misma de sus manifestaciones estéticas, especialmente en lo que concierne al carácter vulnerable o provisorio presente en ellas. Uno de los autores que ha problematizado la incorporación y/o exclusión de los objetos de uso cotidiano al campo de la historia del arte es Keith Moxey (2009), para quien teniendo en cuenta el interés que despiertan las visualidades promovidas por ciertos objetos, es que se los engloba en el campo de los estudios de la imagen. Tanto Santantonín como Grippo han recurrido a dispositivos cotidianos y a veces perecederos para producir sus obras, si bien la irradiación (histórico-artística, semiológica) de cada pieza trascendería la utilización de esas sustancias de base (papel, alambre, papas, cables). De ahí que ambos participen de las antologías, análisis o estudios críticos sobre el arte argentino, en consideración a sus aportes al campo cultural. Vamos a sus componentes fundamentales. Moxey enfatiza el peso de la carga emocional que los objetos (estéticos/artísticos o no) desencadenan, los sentimientos y las percepciones que surgen a partir de la mera presencia de esos objetos involucrados. Desde esa perspectiva los trabajos señalados cubren otras magnitudes que implican aspectos ontológicos ligados a los procesos, al tiempo y a su accionar sobre las sustancias visibles. Juan Martín Prada, referente de Estudios Visuales, nos brinda nuevas vías para pensar la dimensión ontológica de la imagen al concebirla como reemplazo de las intenciones o realidades a las cuáles esa misma imagen alude o describe, dando espacio a una "progresiva independencia del mundo de las representaciones, hacia la que emigra el sentido y el conocer. En cierto modo lo visual se ha convertido en pensamiento y no es ya meramente su resultado, medio o lenguaje» (Prada, 2005: 131). Si bien la imagen actúa y opera como «arrastre» en el intento de crear una ilusión de lo existente, hoy podemos analizar a las visualidades como desprendimientos de esa referencia previa.

La organización de determinados objetos (reales, tangibles) en las instalaciones de Santantonín y Grippo recrea imaginarios sociales que se direccionan hacia una materialidad rudimentaria, primitiva e indómita, con fases de transformación y caducidad. Sería útil rememorar la diferenciación que Arjun Appadurai establece 
entre las mercancías (de valor económico), las imágenes y las «cosas» que circulan en los diferentes paisajes culturales. Las «cosas en movimiento» conforman diferentes imaginarios sociales que «iluminan su contexto social y humano» (Appadurai, 1991: 19) separándose de la pura mercancía suscrita al enclave económico y financiero (si bien para el autor las mercancías pueden ser leídas en clave intercultural y en conexión con la sociedad por donde transitan y se producen los intercambios comerciales). Para Appadurai la vida social de esos objetos se inscribe en constelaciones epocales, en «ordenamientos simbólicos y (trans)discursivos» o en «formaciones culturales» (Brea, 2015: 8). A partir de estas consideraciones es que las "cosas» de Santantonín o las papas de Grippo admiten otra vía de análisis que, si bien presenta algún contacto con la visión appaduriana sobre los objetos circulantes ${ }^{2}$, conlleva a experiencias de temporalidad, inestabilidad y dispersión. El cuestionamiento de la dimensión estética a la cual se refiere Keith Moxey podría aplicarse tanto a los relieves monocromos como a los tubérculos cableados. Son objetualidades que promueven la expansión, la propagación y la interpelación del espacio. En el caso de Rubén Santantonín, más que una producción visual alineada con las experiencias ligadas al informalismo, su poética "fue un eslabón canalizador de las experiencias objetuales del Di Tella. En la repetición de montículos o formaciones extrańas, estas "cosas" configuraron un cuerpo de obra inédito y difícil de categorizar" (Lucero, 2017). Respecto a Víctor Grippo, recordemos que su trayectoria ha sido largamente observada desde la égida del conceptualismo a partir de su participación en el Grupo de los 13 en el CAYC, liderado por Jorge Glusberg. Términos como «opacidad» o «arte conceptual» le sirvieron al propio Glusberg para referirse a la construcción de una identidad visual anclada en los conceptos y en la semiología, donde, citando a autores como Marx, Althusser o Gramsci, definió al arte como «una forma de significación de la realidad, es decir, un sistema semiológico cuyas leyes y mecanismos han comenzado a ser explorados» (Glusberg, 1972: 3). Varios años más tarde, ampliaría su apuesta hacia un conceptualismo regional y bosqueja una posible la retórica latinoamericana en tensión con el subdesarrollo. Desde esta perspectiva, describió los procesos creativos como sistemas de signos artísticos, subrayando las representaciones imaginarias suscitadas en el espectador a partir del entorno político y social, donde el arte como idea sería "la manifestación de una opacidad revolucionaria, opuesta a la conciencia engañosa de las ideologías, y representa una real problemática latinoamericana» (Glusberg, 1978: 3). El énfasis en las condiciones de producción del hecho artístico inscribe la obra de Grippo en esta "retórica latinoamericana» pero sus recursos visuales merecen una lectura superadora de las categorías ancladas en la semiología.

Hemos utilizado la expresión «objetualidades vulnerables» para referirnos a las obras de Rubén Santantonín y Víctor Grippo. Si bien el propio Santantonín estableció diferencias entre las cosas y los objetos, optando por la denominación de "cosas" para estas obras de los años '60, entendemos que también podría aplicarse la noción de "objetualidades». El sufijo de la palabra indica la "cualidad de...", por lo tanto los rasgos estéticos, las cualidades o las características sensoriales de estas producciones artísticas se tornan derivas, extensiones o ramificaciones del objeto en sí mismo. Funcionarían como una readecuación del término (objeto) excediéndolo y aglutinando aspectos de lo sensible que en este artículo pretendemos enfatizar. Por otro lado proponemos abordar la noción de vulnerabilidad en diálogo no solo con la materialidad que determina y sustenta a estas manifestaciones visuales, sino enfati- 
zando la temporalidad y la transitoriedad que afecta a los objetos. Para establecer un contrapunto, repasemos los términos que ha desarrollado Florencia Garramuño para referirse a lo vulnerable en la poesía de Marcos Siscar y en el arte de Ernesto Neto. Tanto en la escritura de Siscar como en las instalaciones de Neto «el imperio de una sensibilidad exacerbada muestra algo de esta vulnerabilidad tornada resistente y de la cual emanan poderes intensos» (Garramuño, 2009: 53). En el caso del escritor, la cualidad de un sujeto caminante se torna sensible en su contacto con el exterior para tornarse perceptible/penetrable al otro, virando hacia lo que la autora llama la «destitución del sujeto». Respecto a Ernesto Neto, la introducción de elementos como telas transparentes de nylon o gasa remite a una "vulnerabilidad tornada colosal sitio hospitalario». En ese sentido existe una mirada de lo vulnerable cimentada en la fragilidad del sujeto (hasta su licuefacción o fusión con el otro) o bien en la blandura y/o liviandad de componentes que a su vez moldean una resistencia por las proporciones de tamańo, aspecto que hace del arte una instancia facilitadora de experiencias, lo que según Garramuño recuerda el ideario de Lygia Clark. Agregaríamos que la obra de Neto exterioriza una reterritorialidad y localización de los volúmenes blandos que envuelven al espectador, creando un ámbito de protección y abrigo corporal en sincronía con un estado de afectividad colectiva. En algunas series de formaciones alargadas (una suerte de tubería humana) emergen analogías con perfiles biológicos, con dinámicas del crecimiento o del desarrollo anatómico que cohabitan en los organismos físicos. La magnitud de sus instalaciones va forjando hábitats humanos disponibles para el usufructo inmediato a modo de microclimas visuales, táctiles y seductores, generando situaciones de comunidad, convivencia, solidaridad y energía creativa que se comparte con el público participante (Figuras 5 y 6). Dichas peculiaridades ubicarían el trabajo de Neto en una tipología de vulnerabilidad diferente a las propuestas de Santantonín o Grippo.

Suely Rolnik (2008) ha mencionado el estado de vulnerabilidad en relación con el cuerpo vibrátil al puntualizar las prácticas artísticas de Lygia a fines de los años '60 y comienzos de los '70. Para Rolnik el sujeto es capaz de establecer vínculos con su entorno a través de la percepción, por la cual vivencia al mundo como un mapa de formas, y de la sensación, mediante la que experimenta aquello que lo rodea como un campo de fuerzas. Es a través de la capacidad subcortical signada por cuerpo vibrátil que nos tornamos elásticos o dúctiles al/hacia el otro ${ }^{3}$. No obstante, para revisar las producciones de los dos artistas argentinos citados nos resulta más adecuado y pertinente pensar un abordaje de lo vulnerable direccionado hacia los procesos de deterioro y descomposición, y por ende, a una incidencia primordial de lo temporal, más que en relación a la maleabilidad o permeabilidad.

Antes de cerrar estas reflexiones podríamos bosquejar una especie de genealogía de objetualidades vulnerables en las prácticas artísticas argentinas de la década del '60, un escenario en el cual Rubén Santantonín ha ocupado un territorio indudable. Más allá de la compleja elaboración de artefactos y ambientes multifacéticos que integraron "La Menesunda» de 1965, donde trabajaron el propio Santantonín y Marta Minujín junto a Pablo Suárez, David Lamelas, Floreal Amor, Rodolfo Prayón y Leopoldo Maler 4 , recordemos «Nosotros afuera», un gigantesco huevo de yeso y madera que Federico Peralta Ramos montó en el mismo año (luego destruido), o los objetos elaborados por la artista alemana Narcisa Hirsch con Walter Mejía y Mari-Louise Alemann, manos de alambres y papel pegado de enormes tamańos que eran utilizados en acciones colectivas de 1968 denominadas «neo-happenings». 
Dichos emergentes nos permiten avizorar una atmósfera mestiza de incertidumbre, juego, nostalgia y perplejidad que acechaba a la Argentina en aquella década, y que se condensaba en estos cuerpos de materialidad frágil, conducente a la erosión, al desgaste, a la pérdida o hacia la posibilidad de evadirse hacia otros mundos posibles.

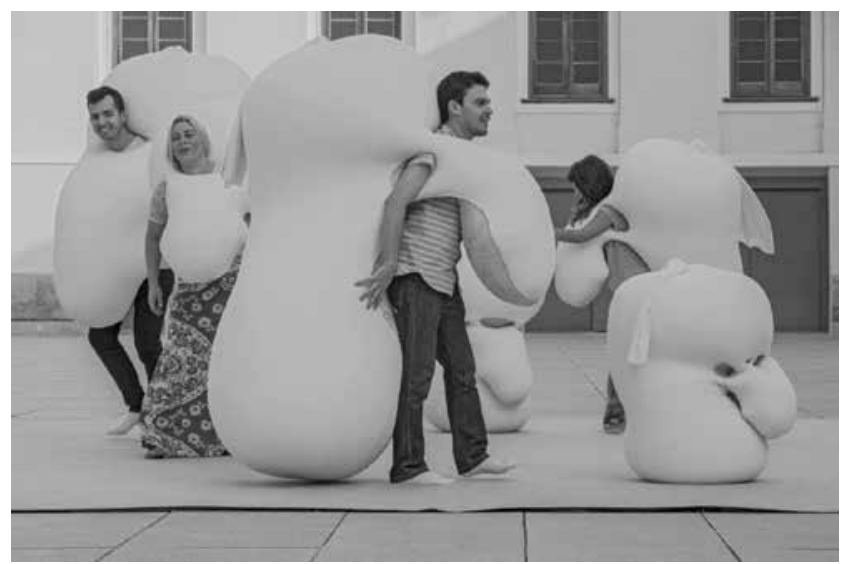

Figura 5. Ernesto Neto

«Humanóides», 2001

Vista de la instalación «Made in Brasil», Casa Daros, Rio de Janeiro, Brasil, 2015 Lycra, tejido, hierbas y bolitas de corcho blanco. Dimensiones variables Fotógrafo: Mario Grisolli

Crédito: Cortesía de Daros Latinamerica Collection, Zürich

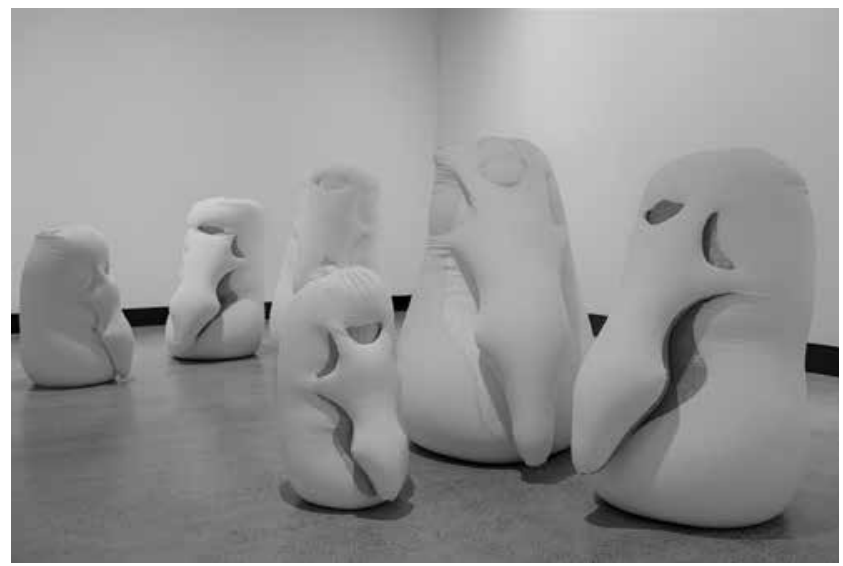

Figura 6. Ernesto Neto «Humanóides», 2001

Vista de la instalación «On the origin of Art», Tasmania, Australia, 2016-2017 Lycra, tejido, hierbas y bolitas de corcho blanco. Dimensiones variables Fotógrafo: Mona/Rémi Chauvin

Crédito: Cortesía de Daros Latinamerica Collection, Zürich 


\section{Notas}

${ }^{1}$ En 1966 Juan Carlos Onganía ejecutó un Golpe militar. El Instituto Di Tella era etiquetado como un lugar dudoso, peligroso por la probable circulación de la intelectualidad de izquierda. A pesar del entorno autoritario, se continuó con la diagramación de muestras, conciertos y pizas teatrales. En el mes de julio ocurrió «La noche de los bastones largos", enfrentamientos entre la fuerza policial y estudiantes y profesores universitarios que fueron agredidos de manera violenta. El periodista Sergio Morero (de Primera Plana) atestiguó el conflicto, registrando el episodio cuando la Policía Federal entraba a la Universidad con bastones largos: «...fue el primer signo de debilidad del gobierno encabezado por el dictador Juan Carlos Onganía, que volteó al presidente constitucional Arturo Umberto Illia con la complicidad de amplios sectores de la burocracia sindical que buscaban su lugar bajo el sol (...)» (Morero, 1996: 7). ${ }^{2}$ Tanto los objetos circulantes que menciona Appadurai y las «cosas» de Santantonín eluden la mercancía.

${ }^{3}$ Esta capacidad de ser vulnerable (en el sentido de flexible) ha sido justamente «reprimida durante muchos siglos, manteniéndose activa sólo en ciertas tradiciones filosóficas y poéticas, que culminaron en las vanguardias culturales de finales del siglo XIX y comienzos del XX, cuya acción se propagó por el tejido social en el transcurso del siglo XX» (Rolnik, 2005: 479).

${ }^{4}$ «La Menesunda (palabra que remitía a confusión) estaba poblada de objetos, artefactos e instalaciones, un engranaje que desmantelaba la noción convencional de "obra de arte" invitando a los asistentes a experimentar diferentes sensaciones, visiones y percepciones en tiempo real. Con el tiempo, quien quedaría para el público masivo como referente central de esta puesta en escena - posiblemente por sus controvertidas apariciones - fue Marta Minujín, pese a la injerencia vital del mismo Santantonín, quien no obtuvo tal reconocimiento» (Lucero, 2017).

\section{Referencias bibliográficas}

Alonso, R. (2013). El espíritu pop. En El espiritu pop. Arte argentino de los sesenta. Mar del Plata: Museo de Arte Contemporáneo, pp. 32-63. Appadurai, A. (1991). La vida social de las cosas. Perspectiva cultural de las mercancias. México: Grijalbo.

BREA, J.L. (2015). Los Estudios Visuales: por una epistemología política de la visualidad. En Estudios Visuales. La epistemología de la visualidad en la era de la globalización (pp. 5-14). Madrid: Akal.

Casanegra, M. (1993). Víctor Grippo. Una estética activa. En Arte Latinoamericano Actual. Exposición, coloquio. Montevideo: Museo de Bellas Artes Juan Manuel Blanes, pp. 13-15. 
Garramuño, F. (2009). Poderes de la vulnerabilidad: Siscar y Neto. ramona 92, revista de artes visuales, Julio 2009. 53-59. Buenos Aires: Fundación Start.

Giunta, A. (2014). ¿Cuándo empieza el arte contemporáneo? Ciudad Autónoma de Buenos Aires: Fundación arteBA.

Glusberg. J. (1972). CAyC: Hacia un Perfil del Arte Latinoamericano (GT-129; GT-129 II). Buenos Aires: Centro de Arte y Comunicación (CAyC), June 12, 1972 [Recuperado en línea] Documents of 20thcentury Latin American and Latino Art. A digital archive and publications project at the Museum of Fine Arts, Houston. (Consultado 19 de diciembre de 2016).

(1978). Aproximación metodológica para una comprensión de la retórica del arte latinoamericano, Centro de Documentación. Museo de Bellas Artes de Caracas, República Bolivariana de Venezuela [Recuperado en línea] Documents of 20th-century Latin American and Latino Art. A digital archive and publications project at the Museum of Fine Arts, Houston. (Consultado 19 de diciembre de 2016).

Grippo, V., Pellegrino, A. y Portillos, A. (1971). Arte de Sistemas. Exh. cat., Buenos Aires: Centro de Arte y Comunicación (CAyC) [Recuperado en línea] Documents of 20th-century Latin American and Latino Art. A digital archive and publications project at the Museum of Fine Arts, Houston. (Consultado 18 de diciembre de 2016).

Kemble, K. y Santantonín, R. (1963). «Rubén Santantonín». En Premio Internacional de Pintura, Catálogo de Exhibición (pp. 58-59), Buenos Aires: Instituto Torcuato Di Tella. [Recuperado en línea] Documents of 20th-century Latin American and Latino Art. A digital archive and publications project at the Museum of Fine Arts, Houston. (Consultado 20 de abril de 2016).

Kemble, K. (2003). 1961 Arte Destructivo. En Cippolini, R. Manifiestos argentinos. Políticas de lo visual (1900-200) (pp. 435-437). Buenos Aires: Adriana Hidalgo.

Lucero, M.E. (2017). Tránsitos de la materialidad. Visualidad, experimento y política en la obra de Rubén Santantonín. En De Jesús, R. y Lucero, M.E. (Comp.) Política, memoria y visualidad: siglos XIX al XXI. E-Book. Barcelona: FOC SL.

Morero, S. ET AL (1996). La noche de los bastones largos. 30 años después. Buenos Aires: Documentos Página/12.

Moxey, K. (2009). Los estudios visuales y el giro icónico. Puntos de suspensión..., Revista Los Estudios Visuales en el Siglo 21, 1, 7-27. Murcia: CENDEAC.

Prada, J.M. (2005). La enseñanza del arte en el campo interdisciplinar de los Estudios Visuales. En Brea, J.L. (Ed.) Estudios Visuales. La epistemología de la visualidad en la era de la globalización (pp. 131-141). Madrid: Akal.

Renart, E., et al (2010). Proceso de creación. En Amigo, R. et al, Palabras de artista. Textos sobre arte argentino, 1961-1981 (56-57). Buenos Aires: Fondo Nacional de las Artes/Fundación Espigas. 
Rolnik, S. (2005). Geopolítica del rufián. En Guattari, F. y Rolnik, S. Micropolítica: cartografias del deseo (477-493). Buenos Aires: Tinta Limón/Traficantes de Sueños.

(2008). Lygia llamando. Mimeografiado de la autora. Rosario: 2da. Reunión de la Red de Investigadores sobre Conceptualismos en América Latina.

Romero Brest, J. (1969). Arte en la Argentina. Últimas décadas. Buenos Aires: Paidós.

Santantonín, R. (1964). Porque nombro "cosas» a estos objetos. En Cosas, Catálogo de Exhibición. Buenos Aires: Galería Lirolay [Recuperado en línea] Documents of 20th-century Latin American and Latino Art. A digital archive and publications project at the Museum of Fine Arts, Houston. (Consultado 14 de diciembre de 2016) 